\title{
Protective Effect of Pomegranate Peel Powder Against Gastric Ulcer in Rats
}

\author{
Magda Soliman Mohamed 1,*(D), Hoda Bakr Mabrok ${ }^{1, *(D)}$ \\ 1 Nutrition and Food Science Department, Food Industry and Nutrition Division, National Research Center, Cairo 12622, \\ Egypt; magdasoliman10@yahoo.com (M.M.); hoda.mabrok@gmail.com (H.M.); \\ * Correspondence: magdasoliman10@yahoo.com (M.M.); hoda.mabrok@gmail.com (H.M.);
}

Scopus Author ID 54883664700 (H.M.) 42062026400 (M.M.)

Received: 8.08.2021; Revised: 16.09.2021; Accepted: 23.09.2021; Published: 16.10.2021

\begin{abstract}
Gastric ulcer is a serious health problem that affects more than $10 \%$ of the World's population. Aspirin is the most common drug causes gastric ulcer also, most of the ulcer drugs have harmful side effects, so studies have focused on finding an alternative natural solution. This work provides a natural solution to protect the gut against ulcers, especially aspirin, by using a diet supplemented with pomegranate peel powder in rats. Levels of active components in pomegranate peel powder were detected using the certified methods. For the biological evaluation, 21 male rats (weight, 140-170 g) were used in three groups, group (1) is a control, group (2) ulcer group, and group(3) (ulcer supplemented group). The duration of the evaluation was 4 weeks. Gastric ulcer was produced by aspirin water suspension (500 mg/kg rat weight). The gene expression of cyclooxygenase-2 (COX-2) and tumor necrosis factor (TNF- $\alpha$ ) were determined by RT-PCR. Pomegranate peel powder $(10 \%$ w/w) reduced the gastric ulcer area and ulcer index, gastric juice volume, and acidity. Pomegranate powder recovers gastric mucus content and gastric tissue at the histological level. Plasma nitric oxide production was raised while plasma TNF- $\alpha$ level was diminutive by pomegranate peel powder. The gastric mucosal TNF- $\alpha$ and COX-2 gene expression were significantly ( $p \leq 0.05)$ down-regulated (2.4 and 12.5 fold-change, respectively) using the pomegranate peel powder. This study introduces pomegranate peel powder (10\%) as a protective food supplement against gastric ulcers.
\end{abstract}

Keywords: pomegranate; gastric ulcer; aspirin; COX-2; TNF- $\alpha$; nitric oxide.

(C) 2021 by the authors. This article is an open-access article distributed under the terms and conditions of the Creative Commons Attribution (CC BY) license (https://creativecommons.org/licenses/by/4.0/).

\section{Introduction}

More than $10 \%$ of the universal population suffer from gastric ulcers, which is related to the imbalance between the secretion of hydrochloric acid, pepsin enzyme, blood flow, prostaglandins, and the presence of stomach bicarbonate [1]. Infection with Helicobacter pylori is a major effective factor of gastric ulcers. Non-steroid-anti-inflammatory drugs (NSAIDs), such as indomethacin and aspirin, are among the most common drugs that cause gastric ulcers [1]. Many studies reported that $15-40 \%$ of chronic NSAIDs users develop ulcers [2]. Likewise, some other lifestyle factors like alcohol drinking, stress, smoking, and imbalanced diets are affected directly in causing gastric ulcers [3]. Several antiulcer drugs were used to prevent and treat gastric ulcers, such as antacids, misoprostol, and proton-pump inhibitor; these drugs have many side effects such as constipation, dizziness, skin rash, stomach pain, and headache were happened after using for a short period if it used for a long time, some other effects like hepatotoxicity and enteric infections may be occurred [2, 4]. A clinical strategy aimed to use a 
selective COX-2 activity inhibitor such as rofecoxib and celecoxib to treat gastric ulcers; the up-regulation of COX-2 expression consequently leads to inflammation-mediated diseases such as gastric ulcers [5]. However, patients exposed to a prolonged intake of such drugs developed cardiovascular disease [4]. Using natural treatments from different plants can prevent or cure gastric ulcers with fewer or no side effects.

Pomegranate (Punica granatum) was used in ancient times in folk medicine to prevent or cure many gastric bowel diseases. All parts of pomegranate have many active compounds such as phenolic compounds (gallagic acid), flavonoids (catechins and quercetin), and anthocyanidin (cyanidin) [6], which possess many biological effects and are reported to act as an anti-inflammatory, antihepatic damage, antioxidant, antibacterial and antiulcer $[6,7]$. Many previous studies evaluated the pomegranate peel extract's effects as antioxidant, antimicrobial, anticancer, antinociceptive, and anti-diabetic [6, 8]. Talaat et al. [9] and Chauhan et al. [10] reported that the aqueous or ethanol extracts of pomegranate peel have a gastro-protective effect against either indomethacin or aspirin induced-gastric ulcer model in rats. Ifora et al. [11] reported that pomegranate rind extract affects inflammation via down-regulating cyclooxygenase- 2 protein expression in ethanol-induced gastric ulcers in rats. The present study may provide an economical way to prevent, reduce or treat gastric ulcers using pomegranate peel powder at the level of $10 \%$ of the rat diet.

\section{Materials and Methods}

\subsection{Plant material and chemicals.}

Pomegranate fruits were purchased from the local market, Cairo, Egypt. Pomegranate peels were collected, dried in a hot air oven at $40^{\circ} \mathrm{C}$, and ground. All chemicals and reagents were of analytical grade.

\subsection{Chemical and antimicrobial evaluation of pomegranate peel powder.}

Total phenolic acids and total flavonoids levels were analyzed using the methods of Saeedeh and Asna [12] and Ordon et al. [13], respectively. Total anthocyanin as cyanidin-3O-glucoside was measured according to the method of Sims and Gamon [14]. Radicalscavenging activity (antioxidant power) of pomegranate peel powder was evaluated using DPPH according to the method of Lee et al. [15]. The antimicrobial activities of pomegranate peel powder were studied against seven bacterial strains and three fungal strains (obtained from the National Research Centre, Cairo, Egypt) using the disc diffusion method according to the method of Aliakbarlu et al. [16].

\subsection{Rats and diets.}

Male rats (Sprague Dawley, 140-170 g) were obtained from the Food Technology Research Institute animal house, Agriculture Research Centre, Giza, Egypt. The animal experiment was approved by the Agriculture Research Centre Committee and followed the recommendations of the National Institute of Health Guide for Care and Use of Laboratory Animals (Publication No-85-23, revised 1985). Animals were housed in cages under controlled temperature and humidity $\left(23 \pm 1^{\circ} \mathrm{C}, 55 \pm 5 \%\right.$ humidity, and 12-h light: 12-h dark cycle). Animals were fed either a basal diet or a basal diet supplemented with pomegranate peel 
powder 10\%. Diet composition prepared according to AIN-93M diet [17] (Table 1), water, and food were given ad-libtium.

Table 1. Composition of the experimental diets.

\begin{tabular}{l|c|c|c} 
Ingredients & Group 1 & G/kg & Group 3 \\
\hline & & 150 & 150 \\
\hline Casein & 150 & 40 & 40 \\
\hline Sunflower oil & 40 & 100 & 100 \\
\hline Sucrose & 100 & 50 & 50 \\
\hline Cellulose & 50 & 35 & 35 \\
\hline Mineral mixture & 35 & 10 & 10 \\
\hline Vitamin mixture & 10 & - & 515 \\
\hline Pomegranate peel powder & - & 615 & 1000
\end{tabular}

\subsection{Experimental design.}

Twenty-one male rats were divided into three groups (seven rats for each group) after the adaptation period (rats were fed on a basal diet for seven days). Group 1 and Group 2 served as normal-control and ulcer-control groups, respectively, rats of both groups fed on basal diet. Rats in group 3 were fed on a basal diet supplemented with pomegranate peel powder $(10 \%)$. The dietary intervention duration was 30 days. On day 31, rats fasted for twenty-fourhour. A single dose of aspirin water suspension $(500 \mathrm{mg} / \mathrm{kg}$ body weight) [18] was given to each rat in group 2 and group 3 (oral gavage) to induce ulcer. The rats of the normal control group received only vehicles. After $6 \mathrm{~h}$ of induction, the animals were anesthetized and sacrificed. Blood samples were collected on heparinized tubes. Plasma was separated by centrifugation at $3000 \mathrm{rpm}$ for 15 minutes. Hemoglobin was determined using Drabkin's method [19]. Plasma nitric oxide was determined by nitric oxide colorimetric assay kit [20]. ELISA assay was used to measure tumor-necrosis-factor- $\alpha$ (TNF- $\alpha$ ) in plasma. [21]. Kidney, liver, heart, and spleen were removed and weighed. The esophageal end was tied then the stomach was removed. Stomach content was collected then washed with saline. Stomach content was centrifuged for $10 \mathrm{~min}$ at $3500 \mathrm{rpm}$ in order to measure total gastric acid [22], gastric volume, and gastric $\mathrm{pH}$. The stomach was incised along the greater curvature. Total ulcerated area $\left(\mathrm{mm}^{2}\right)$ and the number of ulcers per rat were measured. For histological examination, stomach parts were fixed in neutral buffered formalin (15\%). For mucin measurement [23] and TNF- $\alpha$ and COX-2 gene expression analysis by real time-PCR, parts of the stomach were frozen in liquid nitrogen and stored at $-80^{\circ} \mathrm{C}$.

\subsection{Gastric ulcer evaluation.}

Ulcer index was calculated using severity score and the number of ulcers per rat according to Bongu and Vijayakumar [22]. The ulcer severity was scored as follows: 0 no negative features, 1 gastric tissue with mild histopathological damage, 2 moderate negative features, and 3 severe negative features. The ulcer index and ulcer protection $\%$ were determined using the formula as follows: Ulcer index $=(\mathrm{UN}+\mathrm{US}+\mathrm{UP}) \times 10^{-1}$

Where is: $\mathrm{UN}=$ average of number of ulcers per animal, US=average of severity score, $\mathrm{UP}=$ Percentage of animals with ulcers

$\%$ Protection $=($ ulcer index control group - ulcer index treated group $) /$ ulcer index control group $\times 100$ 
2.6. Gene expression of $C O X-2$ and $T N F-\alpha$.

Total RNA was isolated from gastric tissue $(<50 \mathrm{mg})$ with PureLink®RNA Mini kit (ambion ${ }^{\circledR L i f e}$ technologies ${ }^{\mathrm{TM}}$ ) according to manufacturer's protocol. A two $\mu \mathrm{g}$ of total RNA was used to synthesize cDNA with the High capacity cDNA Reverse Transcription kit (ambion ${ }^{\circledR}$ Life technologies ${ }^{\mathrm{TM}}$ ) according to the manufacturer's protocol. Real-time PCR was performed with a Rotor-GeneQ ${ }^{\circledR}$ MDx instrument. The reaction mixture $(25 \mu 1)$ included $1 \mu 1$ cDNA, $12.5 \mu$ l the SYBR ${ }^{\circledR}$ Green PCR master mix (ambion ${ }^{\circledR}$ Life technologies ${ }^{\mathrm{TM}}$ ) and $0.2 \mu \mathrm{M}$ of primers pairs. Primers pairs sequence used were adapted from the literature [24, 25] as follow COX2-FW (tggtgccgggtctgatgatg), COX2-RW (gcaatgcggttctgatactg); TNF- $\alpha$-FW (5ctgaacttcggggtgattg-3); $\quad$ TNF- $\alpha-R W \quad$ (5-gcttggtggtttgctacgac-3); $\quad$ GAPDH-FW (gtattgggcgcctggtcacc), GAPDH-RW (cgctcctggaagatggtgatgg). The PCR amplification condition was $95^{\circ} \mathrm{C}$ for $10 \mathrm{~min}, 45$ cycles at $95^{\circ} \mathrm{C}$ for $15 \mathrm{~s}$, at $60^{\circ} \mathrm{C}$ for $60 \mathrm{~s}$, at $72^{\circ} \mathrm{C}$ for $15 \mathrm{~s}$. PCR water was used as a negative control. The relative fold gene expression was calculated using the delta-delta $\mathrm{Ct}$ method [26]; the target gene expression was normalized to GAPDH expression (housekeeping gene).

\subsection{Statistical analysis.}

The results were expressed as mean $\pm \mathrm{SD}$ and analyzed using one-way ANOVA followed by Tukey's comparison test using the SPSS statistical program. Differences were considered significant at $\mathrm{p} \leq 0.05$.

\section{Results and Discussion}

\subsection{Chemical analysis and antimicrobial activities of pomegranate peel.}

Chemical analysis showed that pomegranate peel powder contains a high concentration of total anthocyanin, total phenolic, and total flavonoids. Based on DPPH radical-scavenging activity \%, pomegranate peel possessed powerful antioxidant activity, as found in table 2 . The antimicrobial activities of pomegranate peel powder are shown in table 3. The highest zone of inhibition $(13 \mathrm{~mm})$ was recorded against $Y$. enterocolitica and $S$. enterica compared with selected studied bacteria. The second highest zone of inhibition was $10.5 \mathrm{~mm}$ observed against B. cereus. However, pomegranate peel was not active against $P$. fluorescens, $L$. monocytogenes, and S. aureus. A minor effect was detected on E. coli. High antifungal activity was recorded by pomegranate peel extract $(7.5 \mathrm{~mm})$ against $A$. niger followed by A. flavus ( 3.8 $\mathrm{mm})$. There was no effect on C. albicans. The negative control was inactive against the selected studied bacteria and fungus.

Table 2. Total phenolic acids, total flavonoids, total anthocyanins content, and DPPH radical-scavenging activity $\%$ of pomegranate peel powder.

\begin{tabular}{l|c} 
& Pomegranate peel \\
\hline Total phenolic acids (mg GA/g) & $410.6 \pm 0.82$ \\
\hline Total flavonoids (mg QE/g) & $18.6 \pm 30.09$ \\
\hline Total anthocyanins (mg cyanidin-3-O-glucoside /100g) & $33.31 \pm 0.25$ \\
\hline DPPH radical-scavenging activity\% & $94.4 \pm 0.01$
\end{tabular}

Values are mean \pm SD $(n=3)$; GA: gallic acid, QE: quercetin 
Table 3. Antibacterial and antifungal activities of tested pomegranate peel powder.

\begin{tabular}{|c|c|c|}
\hline Strains & Control (sterile distilled water) & Pomegranate peel extract \\
\hline & \multicolumn{2}{|c|}{ Zone of inhibition $(\mathbf{m m})$} \\
\hline & \multicolumn{2}{|c|}{ Gram-negative bacteria } \\
\hline Escherichia coli & 0 & $5.5 \pm 0.71$ \\
\hline Salmonella enterica & 0 & $10.0 \pm 1.41$ \\
\hline Pseudomonas fluorescens & 0 & 0 \\
\hline \multirow[t]{2}{*}{ Yersinia enterocolitica } & 0 & $13.0 \pm 1.41$ \\
\hline & \multicolumn{2}{|c|}{ Gram-positive bacteria } \\
\hline Bacillus cereus & 0 & $10.5 \pm 0.71$ \\
\hline Listeria monocytogenes & 0 & 0 \\
\hline \multirow[t]{2}{*}{ Staphylococcus aureus } & 0 & 0 \\
\hline & \multicolumn{2}{|c|}{ Fungus } \\
\hline Aspergillus flavus & 0 & $3.8 \pm 0.35$ \\
\hline Aspergillus niger & 0 & $7.5 \pm 0.70$ \\
\hline Candida albicans & 0 & 0 \\
\hline
\end{tabular}

Values are mean \pm SD $(\mathrm{n}=3)$. The extracts concentration was $200 \mathrm{mg} / \mathrm{ml}$.

\subsection{Animal experiment.}

Some nutritional parameters were done with the tested rats to confirm that they were normal and had no up normal parameters such as initial rats body weights, final body weights, bodyweight gains, total food intakes, the relative weights of the different organs (heart, kidney, lungs, and spleen) and the final hemoglobin levels of the tested rat groups. All results indicated that rats were in good health during the experiments.

\subsection{Histological examination.}

Macroscopic appearance and histological evaluation of stomachs of different tested rat groups are presented in figure 1. The macroscopic of opened stomachs of normal control rats showed a normal morphological appearance (Figure 1A) and hemorrhagic lesions and spots coagulated blood in the ulcer control group (Figure 1C). Furthermore, the stomachs of the pomegranate peel powder pre-treatment group were comparable with a normal control group with minimal lesions in mucosal of gastric (Figure 1E). Histological evaluation of stomachs of normal control rats revealed the normal histological structure of gastric layers (mucosa, submucosa, musculosa, and serosa) (Figure 1B). As found in figure 1 (D), administration of aspirin revealed severe injures, the stomach of ulcer control rats showed focal necrosis of gastric mucosa-associated with inflammatory cells infiltration as well as submucosal edema and submucosal inflammatory cells infiltration. Minimal injuries were seen in the pomegranate peel group revealed the inhibition of the ulcer formation (Figure 1F). Some examined sections from the pomegranate peel treatment group revealed slight submucosal edema, whereas others showed no histopathological changes. Pomegranate peel powder treatment showed a significant reduction in ulcer score $(\mathrm{p}=0.0013)$ (Figure $1 \mathrm{G})$.

\subsection{Stomach injury evaluation.}

Pomegranate peel powder inhibited the gastric ulcer formation induced by aspirin (Table 4). Pre-treatment with pomegranate peel powder had a significant $(p<0.05)$ reduction in ulcer index by $66.42 \%$ as compared by ulcer control rats and significantly $(p<0.05)$ decreased the hemorrhagic injuries by $41.6 \%$ as well (Table 4). Aspirin administration increased total acidity and gastric volume and decreased gastric $\mathrm{pH}$ and mucin content in ulcer control rats compared to normal control rats, indicating ulcer formation. The mucin content in ulcerated tissue of the pomegranate peel powder treatment group was significantly $(p<0.001)$ 
increased by $52.7 \%$ (Table 4). Pomegranate peel powder treatment significantly $(p<0.001)$ reduced the total acidity and gastric volume, while gastric $\mathrm{pH}$ was significantly $(p<0.001)$ increased (Table 4).
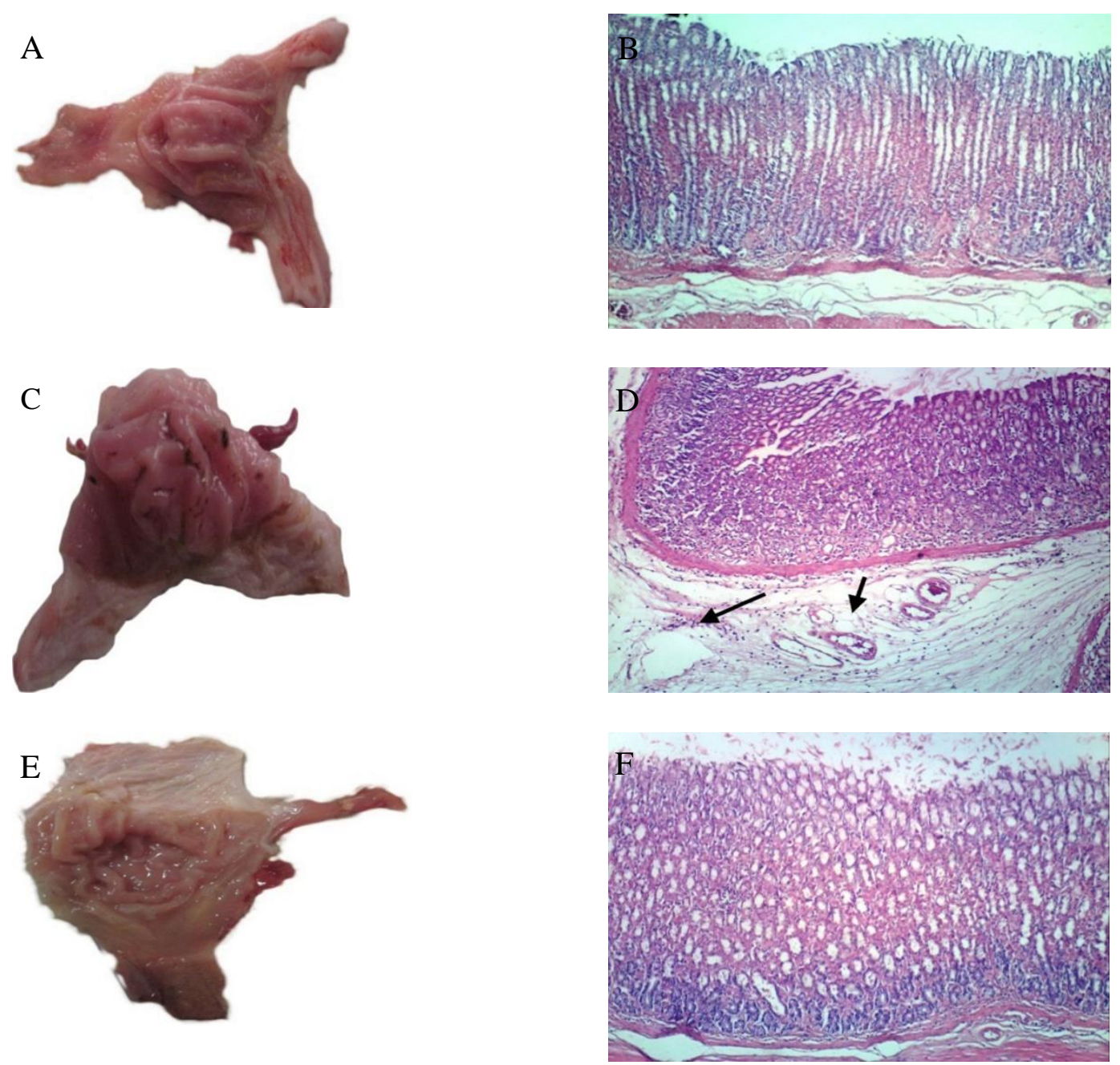

G

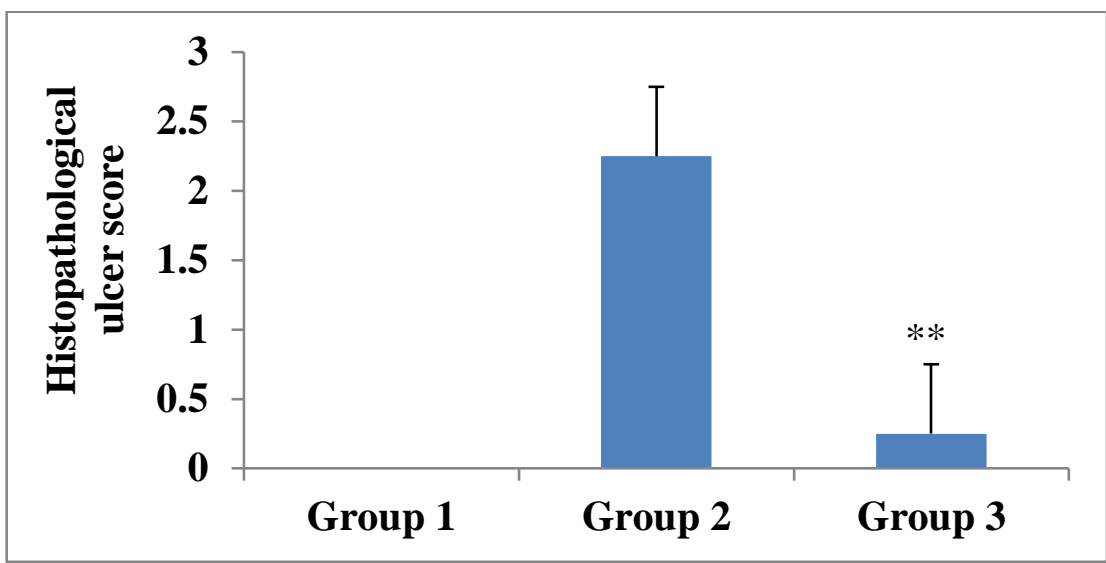

Figure 1. Macroscopic appearance and histopathological examination of the stomach treated with pomegranate peel powder 10\%. A\&B: Stomach of normal control rats showing the normal histological structure of gastric layers, C\&D: Stomach of ulcer control rats showing focal necrosis of gastric mucosa well as sub-mucosal edema, E\&F: Stomach of ulcer rats treated with pomegranate peel powder $10 \%$ showing no histopathological changes, G: histopathological ulcer score (H \& E, $\times 100$ ), Significant values compared to ulcer control** $P<0 \cdot 01$, Group1 (normal control), Group2 (Ulcer control), Group 3 (pomegranate peel). 
Table 4. Ulcer area, index and protection \%, gastric juice volume, $\mathrm{pH}$ and total acidity, and mucin content in tested rat groups.

\begin{tabular}{l|c|c|c} 
& Group 1 & Group 2 & Group 3 \\
\hline Ulcer area $\left(\mathrm{mm}^{2 /}\right.$ rat) & 0 & $42.0 \pm 27.78 \mathrm{a}$ & $17.5 \pm 8.90 \mathrm{~b}$ \\
\hline Ulcer index & 0 & $0.41 \pm 0.0 .28 \mathrm{a}$ & $0.14 \pm 0.07 \mathrm{~b}$ \\
\hline Ulcer protection\% & 0 & 0 & $66.4 \pm 0.07$ \\
\hline Gastric juice volume $(\mathrm{ml})$ & $2.3 \pm 0.10 \mathrm{a}$ & $3.7 \pm 0.47 \mathrm{~b}$ & $2.1 \pm 0.26 \mathrm{ac}$ \\
\hline Gastric juice $\mathrm{pH}$ & $3.3 \pm 0.56 \mathrm{a}$ & $2.2 \pm 0.13 \mathrm{~b}$ & $3.8 \pm 0.35 \mathrm{ac}$ \\
\hline Total acidity $(\mathrm{m} \mathrm{Eq} / \mathrm{L})$ & $2.8 \pm 0.76 \mathrm{a}$ & $5.5 \pm 1.0 \mathrm{~b}$ & $2.9 \pm 0.49 \mathrm{ac}$ \\
\hline Mucin content $(\mu \mathrm{g}$ Alcian blue /g of tissue) & $351.8 \pm 3.83 \mathrm{a}$ & $134.8 \pm 1.53 \mathrm{~b}$ & $285.4 \pm 7.85 \mathrm{c}$
\end{tabular}

Values are mean $\pm \mathrm{SD}$, The same latter in each raw means non-significant difference; different letter means significant difference at 0.05 probabilities. Group1 (normal control), Group2 (Ulcer control), Group 3 (pomegranate peel).

\subsection{Hemoglobin and inflammatory marker in plasma.}

Blood hemoglobin levels didn't differ among all groups (Table 5). Aspirin administration in the ulcer control group resulted in a significant $(\mathrm{p}<0.01)$ reduction in plasma nitric oxide $(\mathrm{NO})$ level and significant $(\mathrm{p}<0.01)$ induction in plasma TNF- $\alpha$ level compared to the control group. Plasma TNF- $\alpha$ level was significantly $(\mathrm{p}<0.05)$ decreased, and plasma NO level was significantly $(\mathrm{p}<0.001)$ increased when ulcerated rats were pre-treated with pomegranate peel powder (Table 5).

Table 5. Blood hemoglobin and inflammatory markers of tested rat groups.

\begin{tabular}{l|c|c|c} 
& $\begin{array}{c}\text { Hemoglobin } \\
(\mathbf{g} / \mathbf{d l})\end{array}$ & $\begin{array}{c}\text { Nitric oxide } \\
(\boldsymbol{\mu m o l} / \mathbf{L})\end{array}$ & $\begin{array}{c}\text { TNF- } \boldsymbol{\alpha} \\
(\mathbf{p g} / \mathbf{m l})\end{array}$ \\
\hline Group 1 & $13.5 \pm 1.07 \mathrm{a}$ & $34.8 \pm 1.91 \mathrm{a}$ & $17.4 \pm 1.43 \mathrm{a}$ \\
\hline Group 2 & $14.0 \pm 1.31 \mathrm{a}$ & $20.0 \pm 4.98 \mathrm{~b}$ & $41.7 \pm 3.28 \mathrm{~b}$ \\
\hline Group 3 & $14.6 \pm 1.03 \mathrm{a}$ & $41.5 \pm 4.76 \mathrm{ac}$ & $23.4 \pm 2.78 \mathrm{ac}$
\end{tabular}

Values are mean $\pm \mathrm{SD}$, the same latter in each column means non-significant difference; different letter means significant difference at 0.05 probabilities, Group1 (normal control), Group2 (Ulcer control), Group 3 (pomegranate peel).
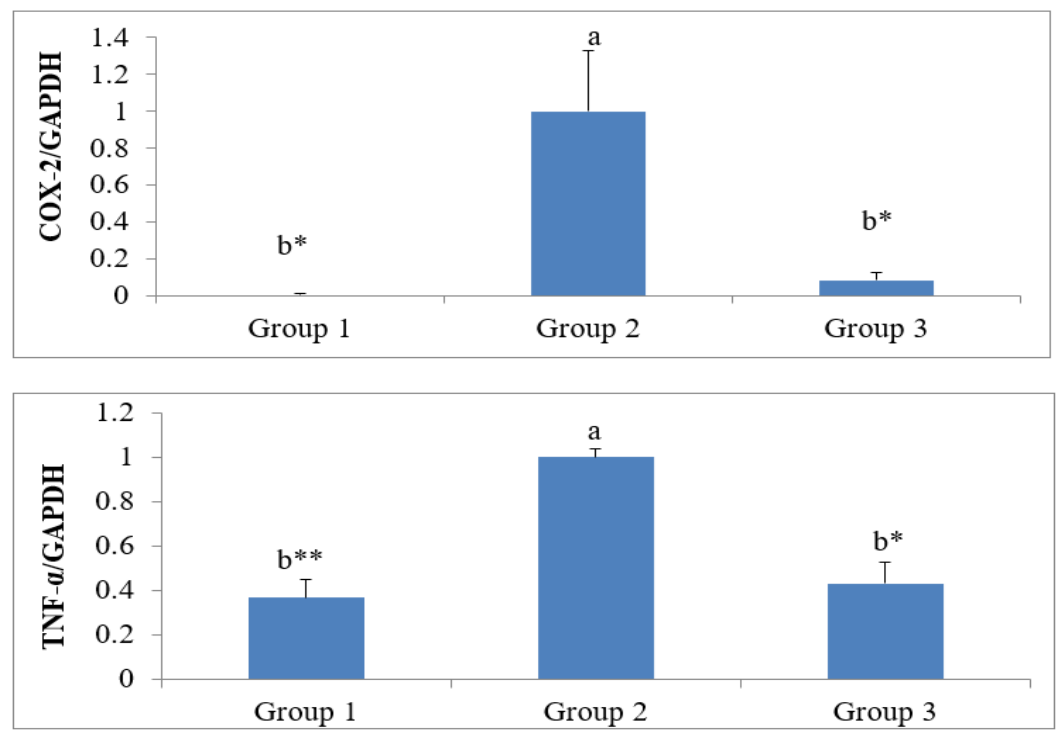

Figure 2. mRNA expression of COX-2 and TNF- $\alpha$ in mucosal gastric of rats fed on a diet supplemented with pomegranate peel powder. The mRNA expression of COX-2 and TNF- $\alpha$ is normalized with housekeeping gene $(\mathrm{GAPDH})$, values are fold change of ulcer control and represent as means \pm SD. Significant values compared to ulcer control $* P<0 \cdot 05 * * P<0 \cdot 01$; the same latter means non-significant difference; different letter mean significant difference at 0.05 probabilities, Group1 (normal control), Group2 (Ulcer control), Group 3 (pomegranate peel). 
3.6. Gene expression of $C O X-2$ and $T N F-\alpha$.

Gastric mucosal mRNA expression of COX-2 and TNF- $\alpha$ were significantly $(p<0.05$, $p<0.01$, respectively) stimulated in ulcer control rats compared to normal control rats (Figure $2)$. Pre-treatment with pomegranate peel was significantly $(p \leq 0.05)$ down-regulated gene expression of COX-2 and TNF- $\alpha$ in gastric mucosal by $91.79 \%$ and $57.01 \%$, respectively (Figure 2).

\subsection{Discussion.}

Gastric ulcer is a very common disease that affects many people worldwide, especially those of low socioeconomic levels [27]. The ulcer is caused by the daily consumption of nonsteroid-anti-inflammatory drugs (NSAIDs) and the Helicobacter pylori infection, which increased gastric acid production and decreased gastric mucus production [1,28]. Using aspirin in rats is a good method that is helping in studying factors that produced ulcers, prevented or reduced the gastric ulcer [29], and the different changes that may happen in some parameters such as prostaglandins, cytokines, and nitric oxide [30]. Polyphenols rich-plants may control gastric ulcers by activating antioxidant performance, controlling $H$. pylori colonization, balancing the regulation of prostaglandins and anti-angiogenic factors, reducing oxidative mucosal changes, enhancing endothelial nitric oxide synthase derived NO, and increasing endogenous mucosal [31].

This work evaluated the effect of the pomegranate peel powder as a polyphenol-rich plant in controlling and preventing gastric ulcers. The chemical analysis, including the total phenols, flavonoids, anthocyanins, antioxidant activities, and antimicrobial properties, was done in pomegranate peel powered. The values of these evaluations were acceptable and encouraged to apply this pomegranate peel powder at the level of $10 \%$ to a diet that provided to rats (one group) for four weeks, then a dose of $500 \mathrm{mg}$ aspirin $/ \mathrm{kg}$-rat-weight were administrated to the rats as a gastric ulcer inducer, the results were compared with other tested groups (normal control and ulcer control groups). The present study indicated that pomegranate peel powder contains high levels of total phenols (as gallic acid) and anthocyanins and has a high potency as an antioxidant, natural plant; this agrees with the findings previously described by Morea and Arya [32]. Also, the antimicrobial effects of the pomegranate peel powder were tested, and results showed that pomegranate peel powder has an inhibitory effect against Grampositive, Gram-negative bacteria, and fungi. These results are in agreement with the previous reports except that $S$. aureus was resistant against pomegranate peel [33], which might be due to using less concentration in the current study compared to previous studies.

Synthetic NSAIDs like aspirin cause mucosal damage by interfering with prostaglandin synthesis, increasing acid secretion, and blocking the diffusion of $\mathrm{H}+[34,35]$. In this study, aspirin $500 \mathrm{mg} / \mathrm{kg}$ increases gastric acidity. Still, treatment with pomegranate peel powder $10 \%$ showed a significant decrease in titratable acidity and gastric volume than the ulcer control rats without pomegranate peel powder $10 \%$. The results of macroscopic appearance and histopathological examination of the stomach confirmed the health effects of pomegranate peel powder at the level $10 \%$ on controlling stomach ulcer since the rats fed with a diet supplemented with pomegranate peel powder $10 \%$ showing normal mucosal layer with slight submucosal edema in some sections, and a significant reduction in histopathological ulcer score, this result in agreement with the result of Abd el-Rady et al. [34]. 
The interruption of prostaglandin synthesis results in impairment of mucosal damage repair, thus facilitating mucosal injury [36]. Prostaglandins are produced by cyclooxygenase (COX-1 and COX-2) enzymes from arachidonic acid. NSAIDs, especially aspirin, can result in a mucosal injury by inhibiting mucosal COX-1 activity and depleting mucosal prostaglandins levels (PGE2) [37]. Aspirin and other NSAIDs administration increase the expression of COX-2 in gastric mucosal [38]. COX-2 is an inducible enzyme and mediator for inflammatory processes and is associated with the formation of pro-inflammatory prostaglandins (PGI2) under pathological conditions [39]. Inhibition of COX-2 is an antiinflammatory target in ulcer healing. COX-2 is up-regulated by inflammatory stimuli, growth factors, and cytokines such as TNF- $\alpha$ [40]. The gastric mucosa injures after aspirin administration is complemented with up-regulation of TNF- $\alpha$ expression [41]. Previous studies have shown that polyphenolic compounds in pomegranate (e.g., kaempferol and Punicalagin) decrease pro-inflammatory cytokines expression as TNF- $\alpha$ [42]. These findings demonstrate that pomegranate peel powder exerts antiulcer and anti-inflammation effects through the reduction of COX-2 and TNF- $\alpha$ gene expression.

It has been stated that NO modulates gastrointestinal mucosal defense, mucus, bicarbonate, gastric blood flow, epithelial barriers, and angiogenesis promotion and is also involved in the pathogenesis of gastric mucosal injury [43]. Nitric oxide is produced by different isomers of nitric oxide synthase (NOS), endothelium NOS (eNOS), inducible NOS (iNOS), and neuronal NOS [44]. NO derived from eNOS isoform exerts cytoprotective effect against gastric damage by NSAIDs; however, NO derived from iNOS exert inflammation and ulcer effect [45]. Aspirin administration depleted gastric-mucosal protective mediators; mucin and nitric oxide in the present study. The reduction of NO level after aspirin administration could be explained by the down-regulation of eNOS expression. Slomiany and Slomiany [46] showed that administration of indomethacin increases the expression of endothelin-1, which suppresses eNOS activity and up-regulated iNOS, leading to gastric mucosal injury in rats. NOS inhibitors that decrease NO production were reported to delay the healing of ulcers [47]. Pomegranate peel powder treatment elevated the previously decreased level of NO, as shown in the current study. Hence, pomegranate peel powder may increase the activity of eNOS and decrease iNOS activity; that hypothesis needs further investigation. Moreover, increasing the NO level by pomegranate peel powder treatment may help to umpire mucin production to protect gastric mucosal cells in aspirin-induced rats.

\section{Conclusions}

The present study indicates that pomegranate peel powder (10\%) has an antiulcer effect in tested rats through decreasing the expression of inflammation markers and the regulation of NO that increases the mucus secretion - this study introducing pomegranate peel powder as an effective and economic antiulcer compound.

\section{Funding}

This research received no external funding.

\section{Acknowledgments}

This research has no acknowledgment. 


\section{Conflicts of Interest}

The authors declare no conflict of interest.

\section{References}

1. Wu, Y.; Murray, G.K.; Byrne, E.M. Sidorenko, J.; Visscher, P.M; Wray, N.R. GWAS of peptic ulcer disease implicates Helicobacter pylori infection, other gastrointestinal disorders and depression. Nat Commun 2021, 12, https://doi.org/10.1038/s41467-021-21280-7.

2. McEvoy, L.; Carr, D.F.; Pirmohamed, M. Pharmacogenomics of NSAID-Induced Upper Gastrointestinal Toxicity. Front. Pharmacol. 2021, 12, https://doi.org/10.3389/fphar.2021.684162.

3. Yim, M.H.; Kim, K.H.; Lee, B.J. The number of household members as a risk factor for peptic ulcer disease. Sci Rep 2021, 11, https://doi.org/10.1038/s41598-021-84892-5.

4. Tai, F.W.D; McAlindon, M.E. Non-steroidal anti-inflammatory drugs and the gastrointestinal tract. Clin Med (Lond) 2021, 21, 131-134, https://doi.org/10.7861/clinmed.2021-0039.

5. Attiq, A.; Jalil J.; Husain, K.; Ahmad, W. Raging the war against inflammation with natural products. Front. Pharmacol. 2018, 9, https://doi.org/10.3389/fphar.2018.00976.

6. Melgarejo-Sánchez, P.; Núñez-Gómez, D.; Martínez-Nicolás, J.J.; Hernández, F.; Legua, P.; Melgarejo, P. Pomegranate variety and pomegranate plant part, relevance from bioactive point of view: a review. Bioresour. Bioprocess 2021, 8, https://doi.org/10.1186/s40643-020-00351-5.

7. Pfohl, M.; DaSilva. N.A.; Marques. E.; Agudelo, J.; Liu, C.; Goedken, M. Slitt, A.L.; Seeram, N.P.; Ma H. Hepatoprotective and anti-inflammatory effects of a standardized pomegranate (Punica granatum) fruit extract in high fat diet-induced obese C57BL/6 mice. Int J Food Sci Nutr. 2021, 72, 499-510, https://doi.org/10.1080/09637486.2020.1849041.

8. Arun, N.; Singh, D.P. Punica granatum: a review on pharmacological and therapeutic properties. Int J Pharm Sci and Res. 2012, 3, 1240-1245, http://doi.org/10.13040/IJPSR.0975-8232.3(5).1240-45.

9. Talaat, R.M.; Abdel-Hakem, N.E.; El-Toumy, S.A.; Samaka, R.M.; Mohamed, A.H.; Ebeed, M.E. Antiangiogenic and Anti-Inflammatory Activity of Punica granatum Peel on Experimentally -Induced Gastric Ulcer in Rats. International Journal of Biological and Chemical Sciences 2014, 5, 42-56, https://doi.org/10.13140/2.1.4458.7522.

10. Chauhan, I.; Sharma, A.; Gangwar, M.; Gautam, M.; Singh, A.; Goel, R. Gastric antiulcer and ulcer healing effects of Punica ranatum $L$. peel extract in rats: role of offensive and defensive mucosal factors and oxidative stress. Int J Pharm Pharm Sci. 2017, 9, 6-11, https://doi.org/10.22159/ijpps.2017v9i5.9851.

11. Ifora, I.; Hasyim, N.; Kardela, W. Cyclooxygenase-2 Inhibitory Effect and Anti-Inflammatory Activity of Pomegranate (Punica granatum L.) Rind Extract. Int. J Pharm Sci and Medi. 2020, 5, 17-22, https://doi.org/10.47760/ijpsm.

12. Saeedeh, A.; Asna, U. Antioxidant properties of various solvent extracts of mulberry (Morus indica $L$ ) leaves. Food Chem. 2007, 102, 1233-1240, https://doi.org/10.1016/j.foodchem.2006.07.013.

13. Ordoñez, A.A.L.; Gomez, J.D.; Vattuone, M.A.; lsla, M.I. Antioxidant activities of Sechium edule (Jacq.) Swartz extracts. Food Chem. 2006, 97, 452-8, https://doi.org/10.1016/j.foodchem.2005.05.024.

14. Sims, D.A.; Gamon, J.A. Relationships between leaf pigment content and spectral reflectance across a wide range of species, leaf structures and developmental stages. Remote Sens Enviro. 2002, 81, 337-354, https://doi.org/10.1016/S0034-4257(02)00010-X.

15. Lee, S.C.; Kim, J.H.; Jeong, S.M.; Kim, D.R.; Ha, J.U.; Nam, K.C. Effect of far-infrared radiation on the antioxidant activity of rice hulls. J. Agric. Food Chem. 2003, 51, 4400-4403, https://doi.org/10.1021/jf0300285.

16. Aliakbarlu, J.; Shameli, F. In vitro antioxidant and antibacterial properties and total phenolic contents of essential oils from Thymus vulgaris, T. Kotschyanus, Ziziphora tenuior and Z. Clinopodioides. Turk. J. Biochem. 2013, 38, 425-431.

17. Reeves, P.G.; Nielsen, F.H.; Fahey, G.C J.R. AIN-93 purified diets for laboratory rodents: final report of the american institute of nutrition ad. hoc writing committee on the reformulation of the AIN-76A rodent diet. $J$. Nutr. 1993, 123, 1939-1951, https://doi.org/10.1093/jn/123.11.1939.

18. Amjad, M.; Tahir, M. Effect of Ethanolic Extract of Coconut (Cocos nucifera) on Aspirin-induced Gastric Ulcer in Albino Rats. J Gastrointest Dig Syst. 2017, 7, 1-6, https://doi.org/10.4172/2161-069X.1000512.

19. Rice, E.W. Rapid determination of total hemoglobin as hemoglobin cyanide in blood containing carboxyhemoglobin. Clin. Chim. Acta. 1967, 18, https://doi.org/10.1016/0009-8981(67)90254-9.

20. Armstrong, F. A. J. Determination of Nitrate in Water Ultraviolet Spectrophotometry. Anal. Chem. 1963, 35 , 1292-1294, https://doi.org/10.1021/ac60202a036.

21. Stepaniak, J.A.; Gould, K.E; Sun, D.; Swanborg, R.H. A comparative study of experimental autoimmune encephalomyelitis in Lewis and DA rats. J Immunol. 1995, 155, 2762-2769.

22. Bongu, S.; Vijayakumar, S. Animal models in experimental gastric ulcer screening-a review. Inte J Pharm Screening Methods. 2012, 2, 82-87. 
23. Corne, S.J.; Morrissey, S.M.; Woods, R.J. A method for the quantitative estimation of gastric barrier mucus. J Physiol. 1974, 242, 116-117.

24. Khan, H.A.; Abdelhalim, M.A.K.; Alhomida, A.S.; Al Ayed, M.S. Transient increase in IL-1 $\beta$, IL-6 and TNF$\alpha$ gene expression in rat liver exposed to gold nanoparticles. Genet Mol Res. 2013, 12, 5851-5857, https://doi.org/10.4238/2013.November.22.12.

25. Chun, J.M.; Kim, H.S.; Lee, A.Y.; Kim, S.H.; Kim, H.K. Anti-inflammatory and antiosteoarthritis effects of saposhnikovia divaricata ethanol extract: in vitro and in vivo studies. Evid-Based Complementary and Altern Med. 2016, 2016, 1-8, https://doi.org/10.1155/2016/1984238.

26. Livak, K.J.; Schmittgen, T.D. Analysis of relative gene expression data using real-time quantitative PCR and the 2- $\Delta \Delta \mathrm{Ct}$ method. Methods. 2001, 25, 402-408, https://doi.org/10.1006/meth.2001.1262.

27. Griffin, M.R.; Scheiman, J.M. Prospects for changing the burden of nonsteroidal anti-inflammatory drug toxicity. Am J Med. 2001, 110, 33S-37S, https://doi.org/10.1016/s0002-9343(00)00634-3.

28. Laine, L.; Barkun, A.N.; Saltzman, J.R.; Martel, M.; Leontiadis, G.I. ACG Clinical Guideline: Upper Gastrointestinal and Ulcer Bleeding. Am. J. Gastroenteroly 2021, 16, 899-917, https://doi.org/10.14309/ajg.0000000000001245.

29. Daglia, M. Polyphenols as antimicrobial agents. Curr Opin Biotechnol. 2012, 23, 174-181, https://doi.org/10.1016/j.copbio.2011.08.007.

30. Farzaei, M.H.; Khanavi, M.; Moghaddam, G.; Dolatshahi, F.; Rahimi, R.; Shams-Ardekani, M.R.; Amin, G.; Hajimahmoodi, M. Standardization of tragopogon graminifolius DC. extracts based on phenolic compounds and antioxidant activity. J Chem. 2014, 2014, https://doi.org/10.1155/2014/425965.

31. Wang, Z.; Hasegawa, J.; Wang, X.; Matsuda, A.; Tokuda, T.; Miura, N.; Watanabe, T. Protective Effects of Ginger against Aspirin-Induced Gastric Ulcers in Rats. Yonago acta medica 2011, 54, 11-19.

32. Morea, P.R.; Arya, S.S. Intensification of bio-actives extraction from pomegranate peel using pulsed ultrasound: Effect of factors, correlation, optimization and antioxidant bioactivities. Ultrasonics Sonochemistry. 2021, 72, https://doi.org/10.1016/j.ultsonch.2020.105423.

33. Chen, J.; Liao, C.; Ouyang, X.; Kahramanoğlu, I.; Gan, Y.; Li, M. Antimicrobial activity of pomegranate peel and its applications on food preservation. J Food Qual. 2020, 2020, 1-8, https://doi.org/10.1155/2020/8850339.

34. Abd El-Rady, N.M.; Dahpy, M.A.; Ahmed, A.; Elgamal, D.A.; Hadiya, S.; Ahmed, M.A.M.; Sayed, ZEA.A.; Abdeltawab, D.; Abdelmohsen, A.S.; Farrag, A.A.M.; Ashmawy, A.M.; Khairallah, M.K.; Galal, H.M. Interplay of biochemical, genetic, and immunohistochemical factors in the etio-pathogenesis of gastric ulcer in rats: a comparative study of the effect of pomegranate loaded nanoparticles versus pomegranate peel extract. Front. Physiol. 2021, 12, https://doi.org/10.3389/fphys.2021.649462.

35. Roa, C.V.; Maiti, R.N.; Goel, R.K. Effect of mid irritant on gastric mucosal offensive and defensive factors. Med. J. Physiol. Pharmacol. 1999, 44, 185-191.

36. Burke, A.; Smyth, E.; Fitzgerald, G.A. Analgesic-Antipyretic Agents, Pharmacotherapy of Gout. In: Goodman and Gilman. Pharma Bases of Therap. Brunton, L.L.; Lazo, J.S.; Parker, K.L. Eds. 11th Edn., McGraw Co. Inco., New York. 2006; pp. 671-715.

37. Peskar, B.M. Role of cyclooxygenase isoforms in gastric mucosal defense and ulcer healing. Inflammopharmacol. 2005, 13, 15-26, https://doi.org/10.1163/156856005774423809.

38. Davies, N.M.; Sharkey, K.A.; Asfaha, S.; Macnaughton, W.K.; Wallace, J.L. Aspirin causes rapid upregulation of cyclo-oxygenase-2 expression in the stomach of rats. Aliment Pharmacol Ther. 1997, 11, 11011108. https://doi.org/10.1046/j.1365-2036.1997.00247.x.

39. Ricciotti, E.; FitzGerald, G.A. Prostaglandins and Inflammation. Arterioscler Thromb Vasc Biol. 2011, 31, 986-1000, https://doi.org/10.1161/ATVBAHA.110.207449.

40. Musumba, C.; Pritchard, D.M.; Pirmohamed, M. Review article: cellular and molecular mechanisms of NSAID-induced peptic ulcers. Aliment Pharmacol Ther. 2009, 30, 517-531, https://doi.org/10.1111/j.13652036.2009.04086.x.

41. Ahmed, I.; Elkablawy, M.A.; El-Agamy, D.S.; Bazarbay, A.A.; Ahmed, N. Carvedilol safeguards against aspirin-induced gastric damage in rats. Hum Exp Toxicol. 2020, 39, 1257-1267, https://doi.org/10.1177/0960327120918306.

42. Serafim, C.; Araruna, M.E.; Júnior, E.A.; Diniz, M.; Hiruma-Lima, C.; Batista, L. A Review of the role of flavonoids in peptic ulcer (2010-2020). Molecules 2020, 25, https://doi.org/10.3390/molecules25225431.

43. Danielak, A.; Wallace, J.L.; Brzozowski, T.; Magierowski, M. Gaseous mediators as a key molecular targets for the development of gastrointestinal-safe anti-inflammatory pharmacology. Front. Pharmacol. 2021, 12, https://doi.org/10.3389/fphar.2021.657457.

44. Lanas, A. Role of nitric oxide in the gastrointestinal tract. Arthritis Res Ther. 2008, 10, https://doi.org/10.1186/ar2465.

45. Li, Y.; Wang, W.P.; Wang, H.Y.; Cho, C.H. Intragastric administration of heparin enhances gastric ulcer healing through a nitric oxide-dependent mechanism in rats. Eur J Pharmacol. 2000, 399, 205-214, https://doi.org/10.1016/s0014-2999(00)00278-8. 
46. Slomiany, B.L.; Slomiany, A. Role of endothelin-converting enzyme-1 in the suppression of constitutive nitric oxide synthase in rat gastric mucosal injury by indomethacin. Scand J Gastroenterol. 2000, 35, 11311136, https://doi.org/10.1080/003655200750056583.

47. Dejban, P.; Eslami, F.; Rahimi, N.; Takzare, N.; Jahansouz M.; Dehpour A.R. Involvement of nitric oxide pathway in the anti-inflammatory effect of modafinil on indomethacin-, stress-, and ethanol -induced gastric mucosal injury in rat. Eur J Pharmacol. 2020, 887, https://doi.org/10.1016/j.ejphar.2020.173579. 